\title{
¿unisul
}

\section{A RUA COMO ALTERNATIVA DE TRABALHO: DESIGN, CONTEXTO ECONÔMICO E SOCIAL E A MISSÃO DE ESTUDOS \\ PROCAD}

THE STREET AS A WORK ALTERNATIVE: DESIGN, ECONOMIC AND SOCIAL CONTEXT AND THE PROCAD STUDY MISSION

Pedro Rocha Sousa Filho; Y Yrisvanya Joana Birino Macedo²; Jackelynne Rodrigues de Oliveira $^{3}$; Ana Lúcia Alexandre de Oliveira Zandomeneghi ${ }^{4}$; Raimundo Lopes Diniz ${ }^{5}$

${ }^{1}$ Mestre em Design, Graduado em Design pela Universidade Federal do Maranhão. E-mail: pedro_rocha_filho@hotmail.com

${ }^{2}$ Mestra em Design, Graduada em Design pela Universidade Federal do Maranhão. E-mail: yrisvanya.jbm@gmail.com

3 Graduanda em Design pela Universidade Federal do Maranhão. E-mail: jackelynne2013@gmail.com

${ }^{4}$ Doutora e Mestra em Engenharia de Produção, Pós Doutora em Engenharia e Gestão do Conhecimento, Graduada em Psicologia, Professora e Orientadora na Universidade Federal do Maranhão. E-mail: ana.zandomeneghi@ufma.br

${ }^{5}$ Doutor em Engenharia de Produção, Mestre em Design, Graduado em Desenho Industrial, Professor e Orientador na Universidade Federal do Maranhão. E-mail: rl.diniz@ufma.br

\section{PALAVRAS CHAVE}

Informalidade; Vendedores de Rua; Design; Economia.

\section{KEY WORDS}

Informality; Street Vendors; Design; Economy.

\section{RESUMO}

$\mathrm{Na}$ esteira de crises econômicas no Brasil, chegamos ao século XXI com o crescimento do desemprego, como consequência, tem-se o aumento de trabalhadores informais nas ruas. A situação contemporânea solicita reflexão, pois o desafio está no trabalho decente, inclusivo e sustentável para todos. Nesse contexto, a pesquisa no âmbito do design é importante, visto que pode proporcionar direcionamentos de melhorias para as pessoas que atuam no setor e para a 


\section{¿UISUl}

economia. De investigação teórica com características aplicada, descritiva e qualitativa, o presente estudo, que é fruto de parceria entre as Universidades Federais do Maranhão e do Paraná, por meio do Programa Nacional de Cooperação Acadêmica na Amazônia - PROCAD/ AMAZÔNIA, busca divulgar vivências acadêmicas de missão de estudos, na cidade de Curitiba, em 2019. A experiência urbana, com abordagem colaborativa, permitiu observar a prática nas ruas, coletar dados e realizar estudo de caso. Portanto, como resultados, explanamse contribuições para a melhoria da atividade.

\section{ABSTRACT}

In the wake of economic crises in Brazil, we reached the 21 st century with the growth of unemployment, as a consequence, there is an increase in informal workers on the streets. The contemporary situation calls for reflection, as the challenge lies in decent, inclusive and sustainable work for all. In this context, research in the scope of design is important, since it can provide direction for improvement for people working in the sector and for the economy. Of theoretical research with applied, descriptive and qualitative characteristics, this study, which is the result of a partnership between the Federal Universities of Maranhão and Paraná, through the National Program for Academic Cooperation in the Amazon - PROCAD / AMAZÔNIA, seeks to disseminate academic experiences of study mission, in the city of Curitiba, in 2019. The urban experience, with a collaborative approach, allowed observing the practice on the streets, collecting data and carrying out a case study. Therefore, as a result, contributions to the improvement of activity are explained. 


\section{INTRODUÇÃO}

Cotidianamente nos centros urbanos de países em desenvolvimento, os vendedores informais são quase sempre visíveis nas ruas, nas calçadas, estacionamentos, parques, feiras, entre outros espaços, que são moldados pela complexa interação do trabalho informal licenciado e não licenciado (Loukaitou-Sideris; Mukhija, 2016; Truong, 2018).

A International Labour Office - ILO, aponta que em muitos países com economias em desenvolvimento, o emprego informal representa uma parte significativa da economia e do mercado de trabalho, desempenhando também, um papel de grande importância na produção, criação de emprego e geração de renda (International Labour Office, 2018). Desse modo, a existência da alta informalidade tem despertado o interesse de pesquisadores e dos gestores de políticas públicas (Chen et al., 2006; Coletto, 2010; Bosch; EstebanPretel, 2012; Chen; Xu, 2017).

Compreender os fatores que determinam a economia informal tornou-se uma questão considerada crucial para os indicadores de desenvolvimento econômico, devido ao déficit que causa sobre a economia (Elbahnasawy et al., 2016). A informalidade também pode colocar os trabalhadores em maior risco de vulnerabilidade e precariedade, além disso, tem um forte impacto na segurança ocupacional, saúde e condições de trabalho em geral (International Labour Office, 2018; Acheampong, 2018).

Nesse contexto, o projeto Comunidades Criativas e Saberes Locais: design no contexto social e cultural de baixa renda, viabilizado pelo Programa Nacional de Cooperação Acadêmica na Amazônia PROCAD / AMAZÔNIA 21/2018, com parcerias estabelecidas entre a Universidade
Federal do Maranhão - UFMA e a Universidade Federal do Paraná - UFPR, contando também com a Universidade do Estado de Minas Gerais (UEMG); busca o desenvolvimento de conhecimento relacionado à região Amazônica, integrando de forma harmônica a dimensão social, econômica e ambiental da sustentabilidade para o desenvolvimento sustentável.

Assim, a proposta de estudo inserida no referido projeto, e que tem por título Design de Base Popular e inserção social: o caso do trabalho informal, foco na função prática; proposto pelo Núcleo de Ergonomia em Processos e Produtos NEPP, da UFMA, e coordenado pelo Prof. Dr. Raimundo Lopes Diniz, procura trazer entendimento acerca dos artefatos de apoio à venda de produtos/serviços dos vendedores de rua, com o objetivo de proporcionar eficiência da função prática (de uso) e, como consequência, maior mobilidade socioeconômica aos trabalhadores informais. O termo "artefato" aqui é entendido como o produto deliberado da mão-de-obra humana (Houaiss, 2001).

Desse modo, o presente texto apresenta um recorte teórico da problemática e divulga vivências acadêmicas da primeira missão de estudos, do projeto citado, dos discentes da pós-graduação, na época, mestrandos do Programa de Pós-Graduação em Design - PPGDg da UFMA, hoje, mestre Pedro Rocha e mestra Yrisvanya Macedo.

$\mathrm{Na}$ oportunidade da missão, entre os meses de abril a agosto de 2019, a discente da graduação em Design da UFMA, Jackelynne Oliveira, também participou das ações na cidade de Curitiba, porém, durante os dois meses iniciais. Assim, contou-se com o apoio da UFPR, no Núcleo de Design e Sustentabilidade, coordenado pelo Prof. 
Dr. Aguinaldo dos Santos e no Laboratório de Ergonomia e Usabilidade, coordenado pela Profa. Dra. Maria Lucia Okimoto.

Atrelado ao contexto da experiência urbana, desdobramentos de estudo de caso e dados coletados na cidade são mais descritos, bem como comparações entre Curitiba e São Luís - MA, que são apresentadas de forma pontual. Visto que, o foco dado aqui está para a aproximação e observação da cidade curitibana e dos vendedores de venda informal, de modo colaborativo, vislumbrando direcionamentos de melhorias para as pessoas que atuam na atividade $e$ direcionamento de estudos futuros no projeto de pesquisa.

Portanto, dentro das competências do design, que requer do profissional da área um repertório variado para $o$ desenvolvimento de projetos, solicita-se do mesmo, também, ações voltadas às necessidades de grupos sociais e ambientais (Ellwanger; Niemeyer, 2013). Para Moura (2018), a atuação do Designer deve ser de responsabilidade, contribuindo para a transformação e a melhoria da qualidade de vida das pessoas. Uma vez que, é de sua responsabilidade às questões sociais, o compromisso com a ética e o desenvolvimento econômico da sociedade (Fornasier; Martins; Merino, 2012).

\section{O PAPEL ECONÔMICO E AS QUESTÕES SOCIAIS DOS VENDEDORES DE RUA EM CONTEXTOS EMERGENTES}

O termo "economia informal" ou "setor informal" se originou a partir de Keith Hart, durante a realização de uma pesquisa no final do ano de 1960 em Gana. No estudo, Hart (1973) observou o expressivo número de pessoas afastadas do setor formal econômico e envolvidas em empregos caracterizados como de auto remuneração, mediante ao fato, empregou-se a expressão "setor informal". Posteriormente, no início dos anos 70, o termo foi novamente utilizado pela International LABOUR, quando pesquisadores da ILO International Labour Office realizaram uma pesquisa empírica no Quênia (Coletto, 2010).

Assim, a economia informal abrange os empregos que não estão inseridos dentro de um setor formal com regras previamente estabelecidas pelo governo. Cross (2000) defende que a economia informal compreende as pessoas que trabalham cotidianamente com bens e serviços sem qualquer respaldo legal, ou seja, com ocupação ilegal de locais de trabalho e ausência de documentos fiscais, além da falta de formalização de contratos de trabalhos com fornecedores e clientes. Para Ruzek (2014), a economia informal é um termo considerado amplo e refere-se aos diversos aspectos da economia de um país que não são tributados ou monitorados pelos governos e não estão incluídos no Produto Interno Bruto - PIB, desses países. E Hart (1973), define que a economia informal é um conjunto de atividades econômicas que acontecem sem o devido comprimento de regulamentos burocráticos governamentais.

Sendo os vendedores de rua trabalhadores informais e participantes da economia informal, uma característica particular deles é a sua mobilidade nas atividades diárias, proporcionando $\mathrm{o}$ deslocamento de um lugar para o outro, além da flexibilidade em montar e desmontar seus artefatos de apoio à venda. Podendo aparecer em um momento e desaparecer em outro, o que lhes permite assumir muitos espaços nas cidades na busca pelo sustento pessoal e, muitas das vezes, familiar (Truong, 2018). 
De acordo com a International Labour Office (2015), a maioria das pessoas que trabalha em situações informais não optaram pela escolha pessoal da atividade, mas, sim, devido à falta de melhores possibilidades. Entretanto, Truong (2018) considera que abordar a pobreza como linha direta para a informalidade é complicado, pois, embora a informalidade esteja relacionada com a pobreza, nem todas as pessoas que trabalham na informalidade são consideradas pobres.

Elgin e Oztunali (2014), relatam que as economias dos países desenvolvidos, quando comparadas aos mercados emergentes têm, geralmente, uma grande economia informal, e que o desenvolvimento econômico por si só, não levará à eliminação gradual da economia informal. Implicando assim, em ações inovadoras para abordar a crescente diversidade das situações em que o trabalho informal é realizado (International Labour Office, 2018).

O relatório Work for a Brighter Future de 2019, constatou que mais de 2 bilhões de trabalhadores $(61,2 \%$ da população empregada mundial) fazem sua vida na economia informal. Geograficamente, o emprego no setor informal, mostra um cenário impressionante: na África, $85,8 \%$ do emprego é informal; na Ásia e no Pacífico chega na proporção de $68,2 \%$; nos Estados Árabes, 68,6\%; nas Américas, 40\%; e na Europa e na Ásia Central, pouco acima de $25 \%$. De maneira holística, evidenciou-se no relatório que $93 \%$ do emprego informal presente no mundo está nos países emergentes e em desenvolvimento. No Brasil, como exemplo, o índice de informalidade é de 46\% (International Labour Office, 2018).

Os dados demonstram a representatividade que o trabalho informal tem na economia de países em desenvolvimento, podendo ser positiva e/ou negativa. De acordo com Schneider e Enste (2000), em países em desenvolvimento como no Egito e Tailândia, a economia informal foi de grande importância, exercendo cerca de $70 \%$ do PIB no início de 1990. Nesse sentido, para Chen e Xu (2017), a informalidade trata-se de um fenômeno global com incidências em países desenvolvidos e em desenvolvimento.

$\mathrm{Na}$ China, com a redução do emprego informal na economia, observaram-se duas implicações distintas: por um lado, o progresso do país no desenvolvimento humano como o processo de formalização, proporcionando maior renda e melhor bemestar; mas, por outro lado, para o capitalismo, o custo com o trabalho é desafiador, acarretando em despesas sociais sobre os cuidados de saúde, educação e previdência (Chen; Xu, 2017).

Durante o século XX, a visão dominante era que o emprego informal gradualmente ia desaparecer devido ao advento da economia formal moderna (Packard, 2007; Adom; Williams, 2012; Williams, 2015). No entanto, ao longo da última década, notouse um crescente reconhecimento de que o setor informal continua a ser uma característica proeminente de muitas economias no mundo (Williams, 2013). Outra visão relatada no International Labour Office (2018), é que os avanços tecnológicos devem contribuir para o surgimento de novas profissões, o desaparecimento e/ou a modificação de outras, entre elas, a venda de rua.

Segundo Marques e Neto (2010), muitas pessoas que usam as ruas como local de venda, não têm carteira assinada, consequentemente, em muitos casos, trabalham em ambientes insalubres, como: calçadas, praias e/ou em eventos diversos. 
Além disso, também atuam em vias públicas, a pé, carregando a própria mercadoria junto ao corpo, em sacolas, malas ou carrinhos de mão. Há casos em que possuem artefatos de apoio à venda, como: barracas removíveis, trailers, veículos automotivos, tabuleiros e/ou tapete estendido no chão.

Nesse contexto, a proposição de novos direcionamentos e estruturação, sem dúvida, pode contribuir com melhorias aos trabalhadores do setor informal. Visto que habilidades exigidas em ocupações antigas e em novas mudarão e transformarão como e onde as pessoas trabalharão (International Labour Office, 2018).

No viés da sustentabilidade, para Ruzek (2014), ao apoiar os setores informais como os de segmento agrícola, vendedores de rua, entre outros; uma mudança na sociedade pode ser desenhada, visto que possibilitará o declínio do uso de carro nos trajetos de venda, contribuindo para o desenvolvimento econômico sustentável. $\mathrm{Na}$ Índia, desde as reformas da década de 1990, o comércio informal de rua tem desempenhado um papel cada vez maior na economia. E, em março de 2014, foi adotada uma lei federal que protege os direitos dos comerciantes de rua (Salèd, 2018).

\section{A ATIVIDADE DE VENDA NAS RUAS E AS SUAS IMPLICAÇÕES}

No Brasil, assim como nos países em desenvolvimento, uma parcela da população ocupada encontra-se inserida no trabalho informal. Nessa situação, observase de modo geral que, existem relações insustentáveis que implicam na ausência de segurança, na falta de assistência médica de qualidade, na pobreza, na fome e na exploração (Beltrão, 2009). Desse modo, no trabalho informal não há direitos trabalhistas e nem contribuição previdenciária, como consequência, mesmo após anos de trabalho nas ruas, não há uma garantia de aposentadoria para as pessoas que necessitam.

Assim, segundo Menezes e Dedecca (2012), a ausência da contribuição gera a perda dos direitos e expõe os trabalhadores a uma precariedade no trabalho que desempenham, os levando a enfrentarem graves problemas econômicos quando não conseguem mais praticarem suas atividades, devido a falta do sistema de previdência social.

Nesse sentido, a triste realidade dos indivíduos que trabalham nas ruas pode ser caracterizada pela quebra do contrato social, pois, os trabalhadores que não estão incorporados no mercado formal são lançados à própria sorte no cotidiano, $\mathrm{e}, \mathrm{sem}$ uma reação por parte da sociedade, há o comprometimento da cidadania (Ramires, 2001).

Logo, Bernardino e Andrade (2015) apontam que, os impactos do trabalho informal na saúde do trabalhador motivam o surgimento de problemas osteomusculares nas pessoas, geralmente ocasionados pela atividade desgastante de extensas jornadas de trabalho e predominantemente braçal. Em Gana, nas cidades de Acra e Takoradi, Alfers (2009) verificou desigualdades sociais e péssimas condições de trabalho, como: exposição a riscos de incêndios, assédio e violência dos oficiais locais, insegurança e precariedade no saneamento básico.

Nesse cenário, existem várias pesquisas a respeito do trabalho de vendedores de rua e sua atividade de comercialização, como: a atividade informal na Indonésia, que relata sobre planejamento em relação a esses vendedores (Yandi, 2008); de como esta atividade pode agregar ao turismo em Hanoi 
- Vietnã (Truong, 2018); sobre a resiliência destes vendedores ambulante nas ruas da China (Lin, 2018); e outras. Dessa forma, observa-se o interesse acadêmico sobre a temática e os aspectos presentes no trabalho dos empreendedores das ruas.

Em Manaus, por exemplo, que é a capital do estado do Amazonas, Cunha (2010) realizaram um estudo que propôs identificar vivências de sofrimento de vendedores de rua, e, que foram caracterizadas por meio das condições de trabalho, conflitos com os clientes, ausência de benefícios trabalhistas, não reconhecimento social e desvalorização. E, por sobreviverem da atividade, os vendedores informais estão expostos diariamente a diversas condições desfavoráveis para o seu bem-estar físico, tais como: poeira, condições climáticas e o barulho gerado por algumas lojas. Logo, eles se sentem desamparados diante de situações como doenças e velhice.

Na cidade de São Paulo - SP, Martins e Dombrowski (2000) revelam que, existem vendedores de rua que trabalham dentro de trens. E, por se tratar de uma atividade proibida pela empresa operadora do transporte, tais vendedores trabalham com pequenas quantidades de produto dentro de sacos, sacolas, caixas de isopor ou papelão.

Nessa circunstância, a informalidade é um problema social e, por isso, é de responsabilidade do poder público promover o crescimento econômico através das políticas econômicas, garantindo as funções sociais e o acesso aos direitos básicos de cada pessoa como cidadão (Costa, 2010). Então, as soluções para as implicações de saúde e segurança dos trabalhadores, entre outras demandas, no setor informal, devem incluir mudanças econômicas estruturais capazes de gerar empregos que sejam produtivos e regulamentados. Além disso, políticas públicas que contemplem ações que possam incluir medidas jurídicas para a legalização da informalidade com capacitação profissional e ampliação de cobertura de assistência à previdência social (Menezes; Dedecca, 2012).

Para Cunha (2009), a principal motivação para a atividade informal está na falta de oportunidade no mercado formal de trabalho, que é agravada pela baixa escolaridade dos indivíduos e pela reestruturação industrial econômica, que provoca a redução e a eliminação de postos de trabalho. Em vista disso,

A nova organização do capital permite uma maior produção com a exploração de um menor número de trabalhadores, realidade que produz uma contradição, pois parte da sociedade tem apenas a venda de sua força de trabalho como forma de garantir sua sobrevivência. Sob a égide da lógica do capital, o desemprego crônico é escamoteado, naturalizado, como se não houvesse outra "alternativa", senão conviver com ele. A responsabilidade social pelo desemprego é atribuída ao trabalhador que deve buscar suas próprias "soluções", muitas vezes a "saída" possível é a apropriação dos espaços públicos da cidade. (Cunha, 2009, p.84).

Por isso, as principais características dos vendedores de rua é a mobilidade e a flexibilidade nas operações diárias (Yatmo, 2008). Visto que, muitas das vezes, precisam buscar os seus clientes para realizarem suas vendas, e, também, para fugirem da fiscalização, quando não são legalizados por legislações regulamentadoras. Diante disso, artefatos (estruturas) para facilitar a atividades são criados pelas pessoas por meio de conhecimentos empíricos e a partir das diversas complexidades e imposições do entorno das metrópoles, objetivando a 
sobrevivência e rompimento das barreiras socioeconômicas (Valese, 2007).

Nesse contexto, observa-se que as implicações nas ruas são muitas e diversas para os trabalhadores, que dependem da atividade para viverem, pois, em geral, a informalidade é notada pela vulnerabilidade, insegurança e violência. Então, compreende-se que a prática nas ruas é tida como uma subversão das leis e dos padrões formais do mercado na sociedade capitalista, que é alicerçado no trabalho assalariado. E, portanto, o fomento de estudos é importante para a formulação de políticas e programas para promover, garantir e advogar por melhores condições de trabalho na economia informal.

\section{VIÉS DO MÉTODO DE PESQUISA EM MISSÃO}

A ida ao campo de pesquisa foi alicerçada inicialmente com levantamento bibliográfico sobre os temas: venda informal, economia informal, melhoria do trabalho nas ruas. Posteriormente, as vivências acadêmicas urbanas apoiaram-se na abordagem colaborativa.

Tal postura foi utilizada como estrutura de observação e encontros. Dessa forma, as opiniões e estratégias quanto aos artefatos de apoio à venda dos vendedores de rua, colaboradores do estudo, foram levadas em consideração para a busca de soluções relacionadas aos problemas identificados.

Manzini (2015) e Snow (2015) apontam que a colaboração ocorre quando as pessoas se encontram e trocam fontes com o objetivo de criar valores compartilhados. Assim, acredita-se que inovação social acontece quando "mudanças no modo como indivíduos ou comunidades agem para resolver seus problemas ou criar novas oportunidades" (Manzini, 2008, p.61).
Desse modo, os dados da pesquisa de campo (vivências acadêmicas nas ruas), que ocorreram entre os meses de abril a agosto de 2019, foram coletados seguindo os seguintes objetivos: (i) Observações assistemáticas das atividades dos vendedores de rua, anotações em cadernetas de campo e registros fotográficos por meio de câmera de telefone móvel; (ii) Mapeamento dos pontos nos quais a presença dos vendedores de rua era notada (licenciados e não licenciados) com auxílio de mapa virtual gratuito (Google Maps); (iii) Entrevistas semiestruturadas com os vendedores de rua, levantando dados, como: pessoais (nome, idade, sexo, escolaridade, renda e composição familiar), do trabalho (local de trabalho, carga horária, se existe deslocamento, rotina de trabalho) e, questões técnicas sobre o artefato de apoio à venda (se produziu, comprou produzido ou ganhou).

Destaca-se, mais uma vez, que o texto trará o olhar holístico das vivências acadêmicas em missão, nesse sentido, não apresentará resultado aprofundado das entrevistas realizadas com os vendedores e atividades realizadas com os mesmos, como do estudo de caso, por exemplo, que ocorreu nos meses de julho e agosto de 2019, envolvendo reuniões colaborativas com um vendedor de rua licenciado.

\section{RESULTADOS, ANÁLISES E DISCUSSÕES: FRUTO DA MISSÃO DE ESTUDOS}

Curitiba - PR é conhecida por seu planejamento urbano, mobilidade, desenvolvimento social, econômico e ambiental. Assim, a equipe missionária chegou na cidade em 06 de abril de 2019 e, a trajetória do intercâmbio iniciou-se com o olhar voltado para as pessoas e suas idiossincrasias. Conforme o olhar de Corrêa 


\section{GESTÃO \& SUSTENTABILIDADE AMBIENTAL}

(2018), optou-se em "vagar pelas ruas de Curitiba", atravessando-se "pelos prédios e casas, pelos ritmos de abertura das lojas e comércios de rua e pela experiência de estar na cidade", observando o design urbano (Figura 1).

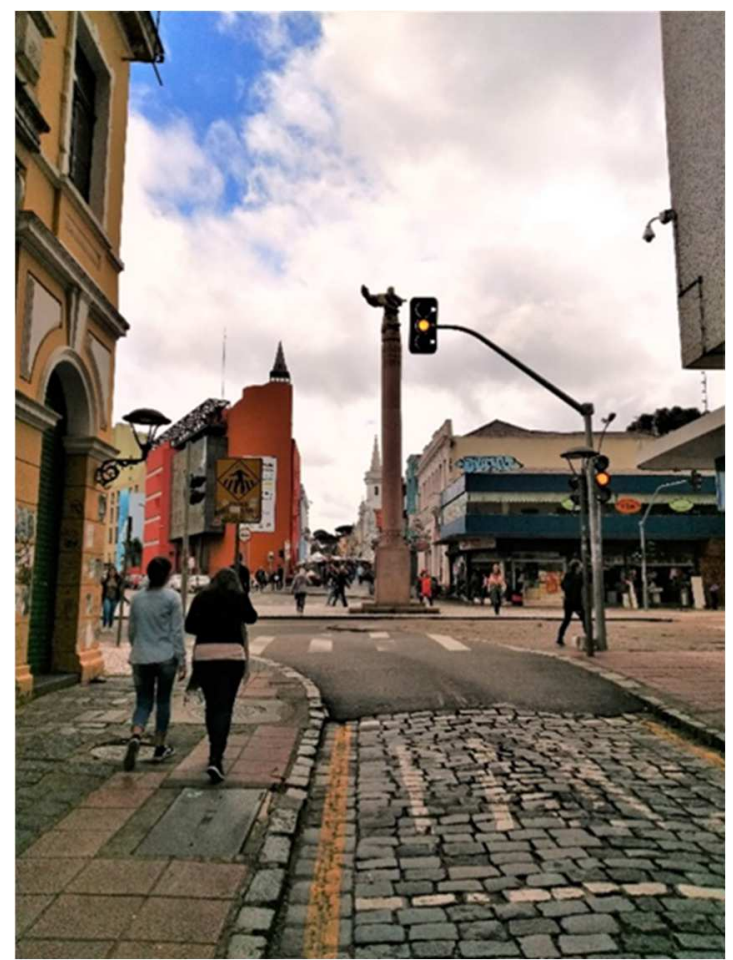

Figura 1. Estar na cidade: entre prédios e os vendedores de ruas.

Aos poucos e com as demais atividades desenvolvidas durante os quatro meses da missão de estudos, como: disciplinas no Programa de Pós-Graduação em Design PPGDesign - UFPR; aprimoramento de conhecimentos no Laboratório de Ergonomia e Usabilidade - LABERG; palestras no projeto Pensar e Fazer Design; reuniões para viabilização de pesquisas com empresas e/ou instituições locais, entre elas, o Centro Brasil Design - CBD; participação em eventos (Design for Sustainable Behavior Research Group; Design Walk In Curitiba; Congresso Brasileiro de Ergonomia - ABERGO e Primeira Jornada do Programa de Pós-Graduação em Design - UFMA), entre outras atividades; pôde-se construir um repertório para a pesquisa de campo com os vendedores de rua da cidade.

A cidade curitibana possui organização ao que tange o vendedor de rua, pois, a prefeitura, através de um processo seletivo, dá a concessão de licença às pessoas para integrar o comércio no centro da cidade. Por outro lado, na cidade de origem dos missionários, São Luís - MA, ainda que a atuação do comércio de rua seja disciplinada pelo Código de Postura de São Luís, Lei 1.790, de 12 de maio de 1968 por meio de licenciamento, percebe-se que, muitas pessoas trabalham de forma não licenciada (ilegal), diferente de Curitiba, que poucos trabalhadores ilegais foram encontrados.

Nesse sentido, através da pesquisa de campo, o mapeamento dos locais de existência de vendedores de rua foi realizado, observando-se maior concentração em feiras urbanas realizadas semanalmente. Também foi possível notar a presença de vendedores em bairros mais afastados do centro, porém, em menor quantidade e sem possuírem licença da prefeitura para praticarem a atividade. Então, compreendeu-se como conhecimentos das vivências:

- Análises das condições de venda dos vendedores de rua entre as cidades de São Luís - MA e Curitiba - PR, além de diferenças legais de venda, organizacionais e da cultura;

- Identificação dos principais modelos de artefatos de apoio à venda e materiais que os vendedores de rua de Curitiba usam (artefato hexagonal com o material bambu (sistemas de encaixes) e artefatos de metal retangulares dobráveis);

- Constatação que a concentração de vendedores de rua acontece com maiores índices nas áreas do Passeio 
público (Parque municipal) e Largo

da ordem (Região do centro histórico em que ocorre uma feira aos domingos). E, nos bairros afastado do centro, é possível encontrar vendedores de rua, licenciados e não licenciados, mas, em quantidade reduzida;

- Evidenciação da necessidade de ajustes nos artefatos de apoio à venda, pois segundo alguns vendedores entrevistados, os artefatos, sejam os de bambu ou os de metal, que foram fornecidos por empresas que possuem parceria com a prefeitura (padronizados), não atendem todas as suas necessidades de venda, assim, desenvolvem adaptações para melhorarem suas atividades;

- Identificação de vendedores licenciados que trabalham com artefatos de apoio à venda diferentes dos padronizados, desenvolvidos e fabricados por eles mesmos, com materiais alternativos e/ou comprados. Além disso, esses artefatos obedecem a critérios de dimensionamentos estabelecidos pela licença da prefeitura, bem como de localização na cidade;

- Reconhecimento de trabalhadores não licenciados (ilegais) que trabalham com artefatos de apoio à venda fabricados por eles mesmos, sem seguir um padrão, bem como de materiais e, sem necessariamente, possuir um lugar fixo de venda nas ruas;

- Constatação da necessidade de melhorias nos artefatos de apoio à venda que os próprios vendedores desenvolveram e/ou modificaram, para que assim, tenham melhores postos de trabalho e, também, melhores resultados na venda de produtos;

No cenário apresentado, é oportuno observar e refletir sobre o cotidiano difícil desses trabalhadores, que empreendem para sobreviverem e são desprotegidos dos benefícios formais de leis trabalhistas; sem contar o preconceito e a violência que sofrem, e ainda, dos limites impostos pelos sistemas governamentais, que oprime e reduz os seus direitos enquanto cidadãos, os colocando ainda mais em vulnerabilidade econômica e social, mesmo quando obtêm o direito a atividade e estão inseridos no desenho urbano de forma organizada.

O contexto de trabalho dos vendedores de rua também proporciona a presença de risco à sua integridade física e à sua saúde mental. Naido et al. (2009), comprovaram, por meio de avaliações, a presença de riscos para a saúde dentro do setor informal, como: lesões físicas, saúde com impactos negativos, distúrbios musculoesqueléticos, exposição a substâncias químicas e estresse psicossocial. E, de acordo com Lund et al. (2016), em Gana e no Brasil, percebe-se que, em uma perspectiva de infraestrutura, vendedores de rua, na maioria das vezes têm acesso limitado a comodidades básicas, como: abrigo para seus bens, banheiros, água, fontes seguras e confiáveis de energia e, segurança contra incêndios.

Diante disso, compreendeu-se por meio de fotos tiradas na cidade de Curitiba, apresentadas a seguir, que a dinâmica da venda é intensa nas feiras de rua (Figura 2) e/ou em eventos organizados pela prefeitura. E, nos muitos parques da cidade, observou-se pouca presença dos trabalhadores. 


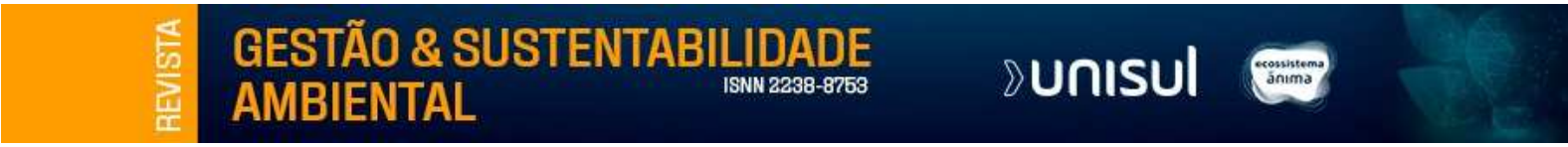

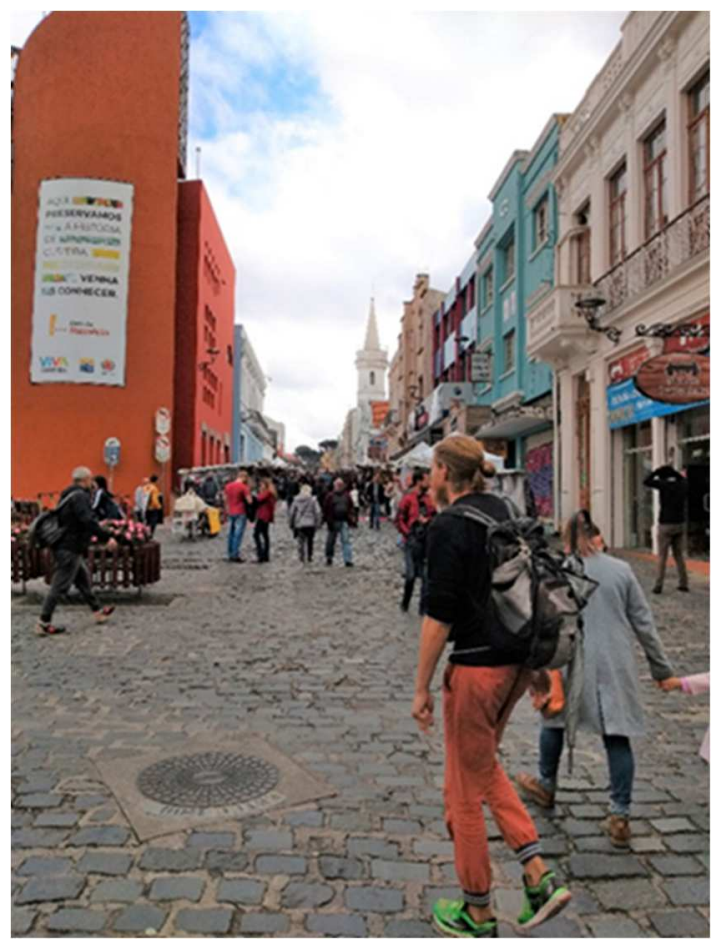

Figura 2. Feira de rua: Largo da Ordem, Curitiba - PR.

Consequentemente, as pessoas que trabalham com artefatos de apoio à venda padronizados e licenciados (Figura 3), obtêm horários e lugares estabelecidos, nesse sentido, as feiras são montadas (aparecem) e desmontadas (desaparecem).

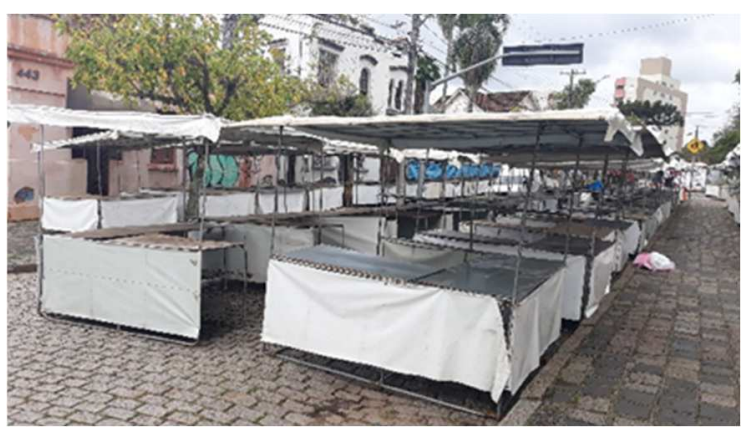

Figura 3. Artefatos de apoio à venda padronizados e licenciados.

Os trabalhadores com artefatos de apoio à venda licenciados (Figura 4), mas, desenvolvidas por eles mesmos sem padrão, também se inserem na mesma dinâmica, contudo, são responsáveis por desmontarem e guardarem seus artefatos de apoio à venda.

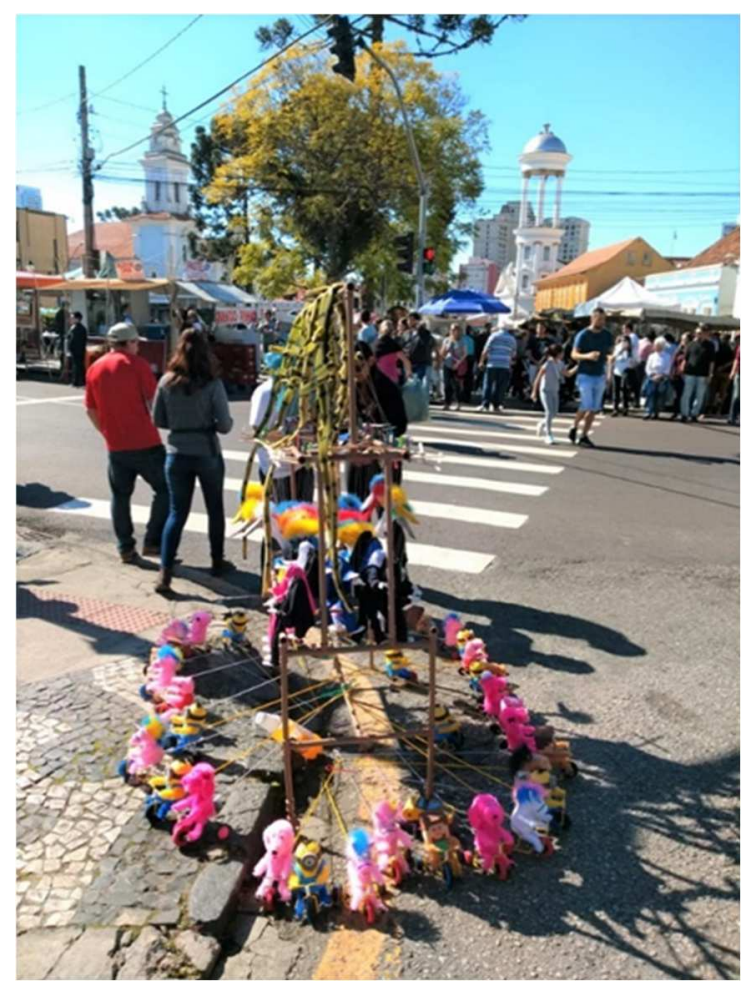

Figura 4. Artefato de apoio à venda licenciado.

Por outro lado, os vendedores que usam o apoio de venda (Figura 5) e o artefato de apoio à venda não licenciados (Figura 6), desenharam seus artefatos para praticarem a venda nas ruas, porém, com a necessidade imprescindível de retirarem-se rapidamente quando notam a fiscalização.

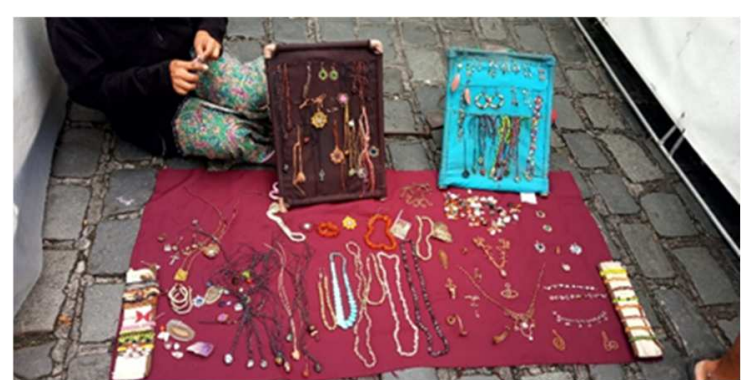

Figura 5. Apoio de venda não licenciado. 


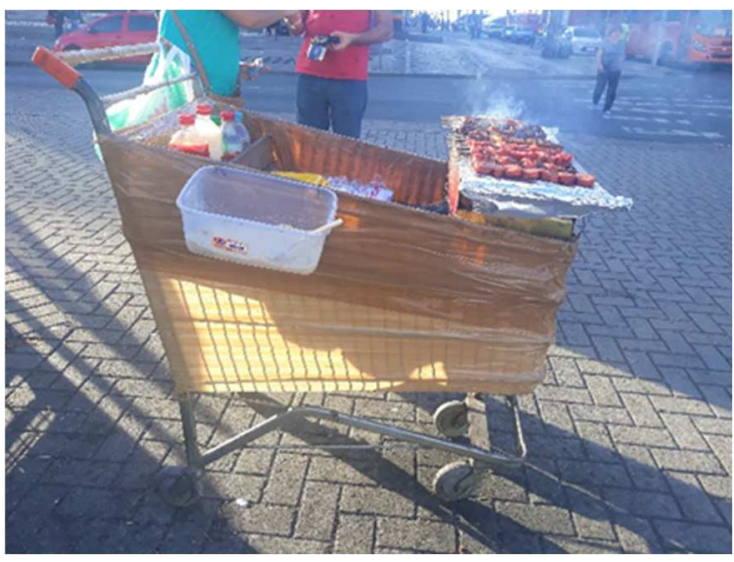

Figura 6. Artefato de apoio à venda não licenciado.

Diante das vivências descritas, registros expostos e problemáticas levantadas, realizou-se um estudo de caso com um vendedor de rua licenciado. Aqui, no presente estudo, o foco não está em demonstrar o detalhamento de todo o estudo de caso, porém, fundamentalmente, tem por desígnio confirmar as observações e dados coletados, como consequência, inferências de melhorias para a atividade de venda realizada nas ruas e direcionamentos para estudos futuros.

Então, por meio da interação entre pesquisadores da UFMA e da UFPR, também com a abordagem colaborativa (envolvendo a cocriação), o vendedor, morador do município Almirante Tamandaré - Paraná, que trabalha nas feiras de Curitiba, foi o protagonista do estudo com os seus saberes.

Uma vez que, o design colaborativo tem por objetivo envolver as pessoas usufrutuárias do projeto/produtos, proporcionando poder de decisão durante o processo e desenvolvimento de novas ideias (redesign). Propôs-se um diálogo aberto, respeitando os saberes e vivências do vendedor, logo, inseriu-se o olhar da fabricação digital (Figura 7), que possibilita a impressão de peças/artefatos em $3 \mathrm{D}$, além de ser uma possibilidade open source (fonte aberta), no qual outras pessoas podem usufruir do trabalho desenvolvido, por meio do acesso à Internet (Figura 8). E, com os critérios da ergonomia e sustentabilidade, vislumbrou-se um novo desenho para o artefato de apoio à venda do vendedor (Figura 9).

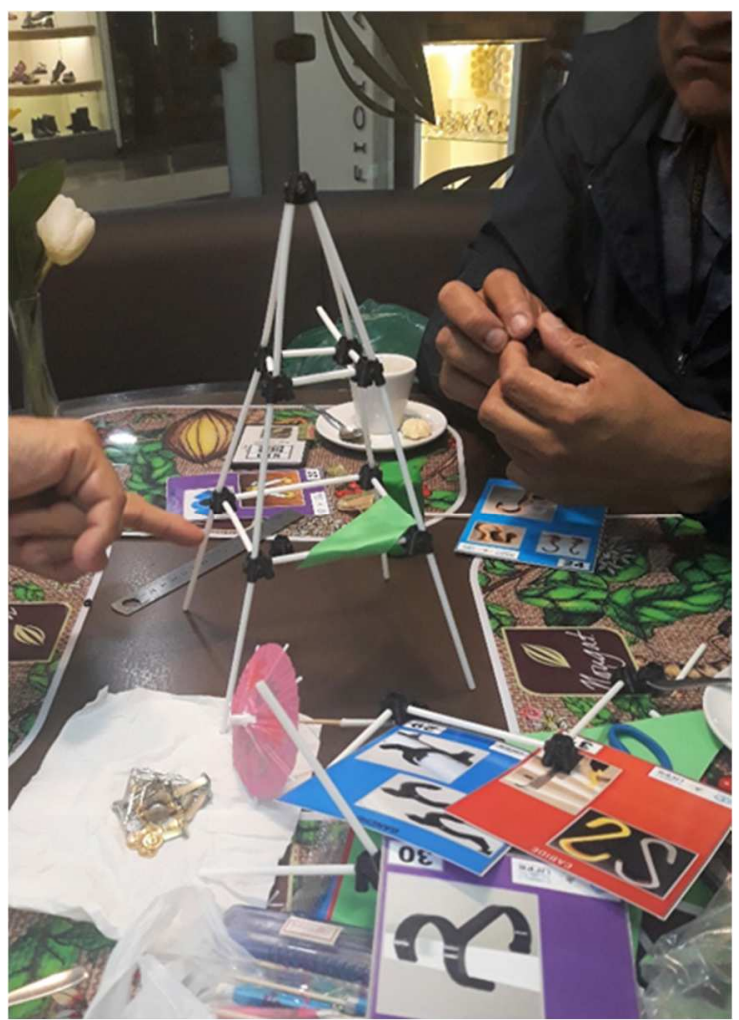

Figura 7. Interação entre pesquisadores e vendedor: o olhar para a fabricação digital.

Observa-se por meio da Figura 7 a abertura de olhar do vendedor para a fabricação digital, que se iniciou através de cartas impressas com variados desenhos de peças em código aberto, encontradas na Internet e relacionadas com a sua estrutura de apoio à venda. Posteriormente, como também se nota no registro, uma peça escolhida pelo vendedor passou por ajustes na modelagem, e foram impressas algumas em escala reduzida para que o mesmo idealizasse as melhorias na sua estrutura de apoio ao trabalho nas ruas de Curitiba. 


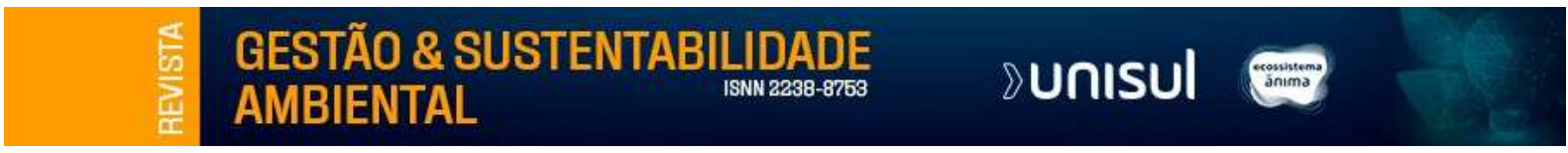

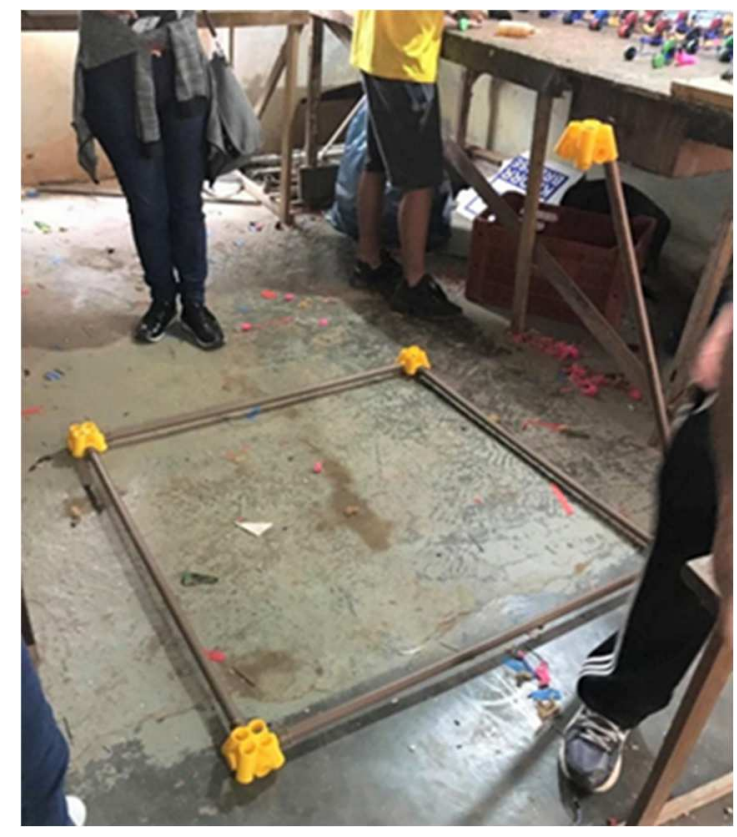

Figura 8. Montagem do artefato de apoio à venda com peças em open source.

Assim, após reuniões e alinhamentos entre pesquisadores e o vendedor, peças em escala normal foram impressas em impressoras 3D, e, como verifica-se na Figura 8, o próprio vendedor começou a preparar a sua nova estrutura com auxílio de peças adaptadas e em código aberto.

Assim, após reuniões e alinhamentos entre pesquisadores e o vendedor, peças em escala normal foram impressas em impressoras 3D, e, como verifica-se na Figura 8, o próprio vendedor começou a preparar a sua nova estrutura com auxílio de peças adaptadas e em código aberto.

Então, a Figura 9 mostra o redesign do artefato de apoio a venda, que antes era retangular, como é possível olhar na Figura 4 , anteriormente apresentada no presente estudo.

Nesse entendimento e por meio do cruzamento dos dados levantados, verificou-se que a atividade informal realizada nas ruas, com o auxílio dos artefatos de apoio à venda, gera as seguintes problemáticas aos vendedores: Postura inadequada e desconforto/dores (ocasionadas pelo transporte dos artefatos pesados, falta de lugar adequado para descanso, alimentação e ausência de banheiro); danos à saúde devido às intempéries (pois estão expostos ao sol, chuva e temperaturas baixas); e, violência verbal (os vendedores informais geralmente recebem insultos de pessoas que não gostam da presença deles).

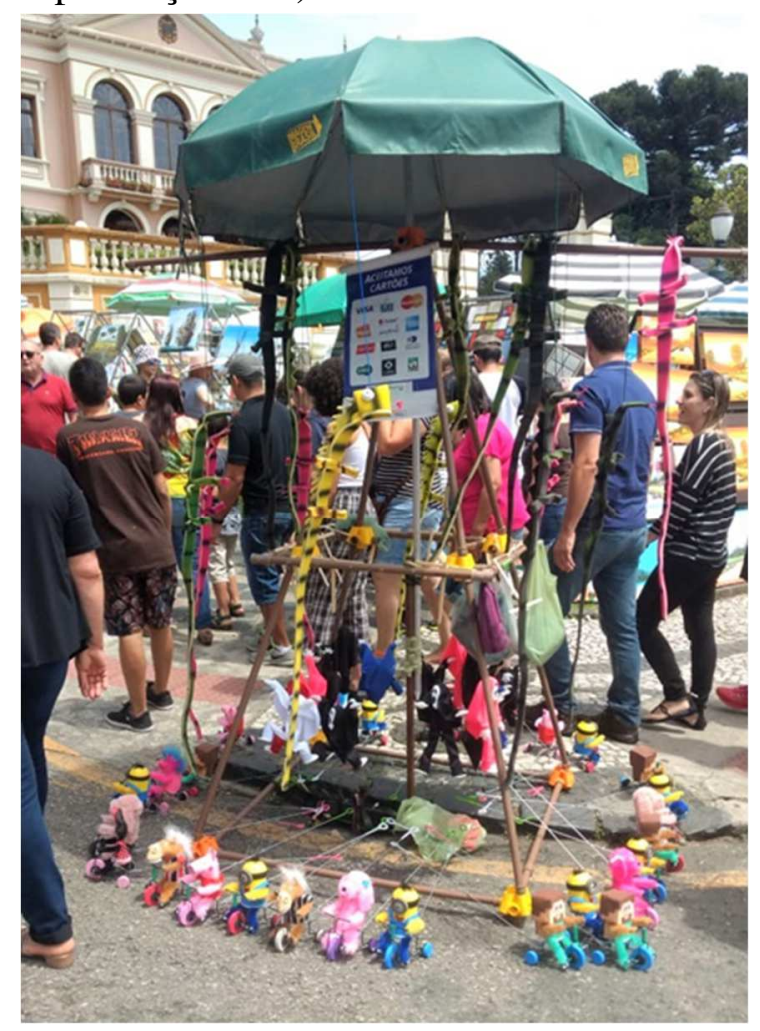

Figura 9. Redesign do artefato de apoio à venda com peças em open source.

Consequentemente, identificaram-se possíveis inferências de melhorias nos artefatos de apoio à venda, como: adequação de manejos (pegas $e$ empunhaduras), utilizados para o transporte das mercadorias (produtos comercializados); ajuste nas alturas de bancadas de atendimentos, que dependem do tipo de atividade desempenhada; proteção contra intempéries, como 
trabalham nas ruas, necessitam de proteção que os auxiliem nessa exposição; e, criação de gavetas/espaços no artefato de apoio à venda, a serem utilizados para guardar itens pessoais, entre outros objetos/produtos fundamentais para a atividade no dia a dia.

No que tange às melhorias do posto de trabalho dos vendedores de rua, os longos períodos de trabalhos podem ser intercalados com pausas durante o dia, ou até mesmo, o uso de apoio para os pés, melhorando a alternância de postura, visando evitar e/ou diminuir dores ocasionadas pela postura ocupacional adotada pelos vendedores.

Diante do exposto, é notório que, o trabalho informal, tanto o licenciado como o não licenciado, requer um conjunto amplo de intervenções e melhorias, levando em conta riscos específicos enfrentados por pessoas em diferentes ocupações, mesmo os que trabalham em locais de trabalho "atípicos" para um melhor desenvolvimento econômico e social de todos (Lund et al., 2016). Portanto, discussões futuras, do projeto de pesquisa, buscarão desenhar soluções efetivas que auxiliem o vendedor de rua e a atividade em si, realizada com artefatos de apoio à venda, verificando com atenção os critérios que levaram a fabricação dos artefatos (suas formas e respectivos materiais) para $\mathrm{o}$ direcionamento de novos modelos de artefatos.

\section{CONSIDERAÇÕES FINAIS}

O estudo não pretende ser um fim, visto que teve como foco a divulgação das vivências acadêmicas em missão de estudos PROCAD, ocorrida na cidade de Curitiba, em 2019. Também, buscou ser um meio de lançar luz sobre reflexões contemporâneas acerca do trabalho nas ruas praticados por indivíduos que, muitas das vezes, encontram-se à margem da sociedade, um dos pontos de investigação do design, no projeto Design de Base Popular e inserção social: o caso do trabalho informal, foco na função prática; proposto pelo Núcleo de Ergonomia em Processos e Produtos NEPP, da UFMA.

O diálogo por meio de entrevistas semiestruturadas permitiu verificar a rotina da atividade de venda, observando os artefatos de apoio à venda, e desse modo, outras informações foram coletadas para alicerçar a dissertação de mestrado desenvolvida por Yrisvanya Macedo, como: a função, criação, produção, uso, motivação para fazer $o$ artefato, manutenção, produto/serviço prestados com as estruturas e descarte das mesmas.

As observações não ocorreram apenas no âmbito da pesquisa, focada na atividade de venda realizada pelo comércio informal das ruas, mas também, com o olhar no conjunto físico e cultural da cidade de Curitiba. Nuances da cidade foram exploradas, tanto a arquitetura, com seus edifícios monumentais, como às pessoas e seu modo de interagir.

Considera-se que a atividade informal desempenha um papel importante na economia, e, na medida que os vendedores de rua criam ou reformulam algo para um fim, ou tentam atender a uma necessidade e resolver um problema, os mesmos criam cursos de ação em direção a uma situação preferível, essa definição abrange a maioria das formas de design. Visto que, "em uma dimensão, design é um campo de pensamento e pesquisa pura, em outra, design é um campo de prática e de pesquisa aplicada" (Friedman, 2016, p. 25). Dessa forma, pensando e fazendo design, com base nos resultados das condições de venda, evidências e identificações, possíveis 
melhorias, no que diz respeito a uma melhor adequação entre o vendedor de rua e o artefato, foram levantadas no estudo.

Os vendedores de rua geralmente deslocam-se com suas estruturas de apoio à venda (artefato) por longas avenidas para garantir o sustento próprio e familiar, pois, comumente, não encontram trabalhos formais. Nesse entendimento, como políticas públicas e legislações não conseguem resolver a demanda, entende-se que o desenho urbano precisa atender os empreendedores das ruas de modo justo e ético, visto que também pagam impostos. Além disso, em cenários de crises atípicas, a exemplo, a crise de pandemia provocada pelo COVID-19 (doença causada pelo coronavírus), que pode impossibilitar ou dificultar a atividade de comercialização presencial, necessita de novos direcionamentos e soluções.

Portanto, os passos iniciais no projeto COMUNIDADES CRIATIVAS E SABERES LOCAIS: design no contexto social e cultural de baixa renda aconteceram com êxito e, com a continuação das ações, novos percursos ampliados serão traçados pelos pesquisadores envolvidos no projeto, respeitando os saberes tradicionais $\mathrm{e}$ locais, para o desenvolvimento socioeconômico sustentável.

\section{REFERÊNCIAS}

Acheampong, R. A., 2019. Spatial planning and the urban informal economy, in: Spatial Planning in Ghana. Springer, Cham. p. 269-288. https://doi.org/10.1007/978-3-030-020118_12

Adom, K., WILLIAMS, C. C., 2014. Evaluating the explanations for the informal economy in third world cities: some evidence from Koforidua in the eastern region of Ghana. International Entrepreneurship and Management Journal, v. 10, n. 2, p. 427-445. https://doi.org/10.1007/s11365-012-0224-5

Alfers, L., 2009. Saúde e segurança ocupacional para comerciantes e vendedores ambulantes em Acra e Takoradi, Gana. ISBN: 978-92-95095-55-7

Beltrão, M. M. A., 2009. Trabalho informal e desemprego: desigualdades sociais. Tese de Doutorado. Universidade de São Paulo. https://doi.org/10.11606/T.8.2010.tde05032010-130328

Bernardino, D. C. de A. M., Andrade, M., 2015. O trabalho informal e as repercussões para a saúde do trabalhador: uma revisão integrativa. Revista de Enfermagem Referência, v. 4, n. 7, p. 149158. https://doi.org/10.12707/RIV14049

Bosch, M., Esteban-Pretel, J., 2012. Job creation and job destruction in the presence of informal markets. Journal of Development Economics, v. 98, n. 2, p. 270-286.

https://doi.org/10.1016/j.jdeveco.2011.08.0 04

Chen, M., Vanek, J., Heintz, J., 2006. Informality, gender and poverty: A global picture. Economic and Political Weekly, p. 2131-2139.

https://doi.org/10.2307/4418269

Chen, Y., Xu, Z., 2017. Informal employment and China's economic development. The Chinese Economy, v. 50, n. 6, p. 425-433. https://doi.org/10.1080/10971475.2017.13 80115

Coletto, D., 2010. The informal economy and employment in Brazil: Latin America, modernization, and social changes.

Springer. 


\section{¿unisul}

Corrêa, R., 2018. Quando a galeria é a cidade. Medium.

https://medium.com/fotocronografias/quan do-a-galeria-\%C3\%A9-a-cidadea8b92a99b49b. (acesso 29 Jul. 2018).

Costa, M. S., 2010. Trabalho informal: um problema estrutural básico no entendimento das desigualdades na sociedade brasileira. Cad. CRH, Salvador, v. 23, n. 58, abr. 2010.

https://doi.org/10.1590/S010349792010000100011

CROSS, J., 2000. Street vendors, and postmodernity: conflict and compromise in the global economy. International journal of sociology and social policy. https://doi.org/10.1108/014433300107890 61

Cunha, A. M., 2009. Trabalhadores de rua: tensões e resistências na luta pelo direito ao trabalho. Revista Katálysis, v. 12, p. 7785. https://doi.org/10.1590/S141449802009000100010

Cunha, S. C. P., 2010. Vivências de prazer e sofrimento no trabalho dos camelôs no centro comercial de Manaus. 2010. $69 \mathrm{f}$. Trabalho de conclusão de curso (graduação) - Universidade Federal do Amazonas, Manaus, AM.

Elbahnasawy, N. G., Ellis, M. A., Adom, A. D., 2016. Political instability and the informal economy. World Development, v. 85, p. 31-42.

https://doi.org/10.1016/j.worlddev.2016.04 .009

Elgin, C., Oztunali, O., 2014. Institutions, informal economy, and economic development. Emerging Markets Finance and Trade, v. 50, n. 4, p. 145-162. https://doi.org/10.2753/REE1540496X500409

Ellwanger, D., Niemeyer, L., 2013. Revisão e reflexão sobre design social, in:
Menezes, M. S., Moura, M. (Org.). Rumos da Pesquisa no Design Contemporâneo: inserção social. 1.ed, ed. Estação das Letras e Cores, São Paulo, v. 1, p. 265-285.

Fornasier, C. B. R., Martins, R. F. F., Merino, E., 2018. Da responsabilidade social imposta ao design social movido pela razão.

http://repositorio.ufsc.br/xmlui/handle/123 456789/1850 (acesso 29 Jul. 2018).

Friedman, K., 2016. Construção de teoria na pesquisa de design: critérios, abordagens e métodos. Arcos Design, v. 9, n. 2, p. 1-30. ISSN: 1984-5596

Hart, K., 1973. Informal income opportunities and urban employment in Ghana. The journal of modern African studies, v. 11, n. 1, p. 61-89. https://doi.org/10.1017/S0022278X000080 89

Houaiss, A., 2001. Dicionário eletrônico Houaiss da língua portuguesa, ed. Objetiva, Rio de Janeiro.

International Labour Organization, 2019. Women and men in the informal economy: a statistical picture (third edition) / Geneva, 2018.

https://www.ilo.org/global/publications/bo oks/WCMS_626831/lang--en/index.htm. (acesso 14 Set. 2019).

ISBN:789221315803

International Labour Organization, 2019. World employment and social outlook: trends 2015.

https://www.ilo.org/wcmsp5/groups/public /---dgreports/---dcomm/---

publ/documents/publication/wcms_337069 .pdf (acesso 14 Set. 2019). ISBN 978-92-2129260-9

Lin, S. L., 2018. "We work like ants... we avoid being troublemaker": An exploratory inquiry on resilience of Chinese street vendors in the urban village. International 


\section{¿Unisul}

Journal of Sociology and Social Policy. https://doi.org/ 10.1108/IJSSP-01-20180008

Loukaitou-Sideris, A., Mukhija, V., 2016. Responding to informality through urban design studio pedagogy. Journal of Urban Design, v. 21, n. 5, p. 577-595. https://doi.org/10.1080/13574809.2015.10 71650

Lund, F., Alfers, L., Santana, V., 2016. Towards an inclusive occupational health and safety for informal workers. New Solutions: A Journal of Environmental and Occupational Health Policy, v. 26, n. 2, p. 190-207. https://doi.org/10.1177/104829111665217 7

Manzini, E., 2008. Design para a inovação social e sustentabilidade (LIVRO): Comunidades criativas, organizações colaborativas e novas redes projetuais, ed. E-papers.

Manzini, E., 2015. Design, when everybody designs: An introduction to design for social innovation, ed. MIT press.

Marques, V.H.P., Neto, J.A., 2010. Análise da organização do trabalho ambulante e suas repercussões - estudo de caso em uma praia de grande atração turística do Rio Grande do Norte, in: XVII Simpósio de Engenharia de Produção. Anais..., ed. UNESP, Bauru.

Martins, R., Dombrowski, O., 2000. Mapa do trabalho informal na cidade de São Paulo, in: Jakobsen, K., Martins, R., Dombrowski, O. (Orgs.). Mapa do trabalho informal. Perfil socioeconômico dos trabalhadores informais na cidade de São Paulo, ed. Fundação Perseu Abramo, p. 2439. Coleção Brasil Urgente.

Menezes, W. F., Dedecca, C. S., 2012. A Informalidade no Mercado de Trabalho
Brasileiro: Rendimentos e principais características. Revista Nexos Econômicos, v. 6, n. 2, p. 11-42.

https://doi.org/10.9771/1516-

9022rene.v6i2.9247

Moura, M. C., 2018. Design para o sensível: Política e ação social na contemporaneidade. Revista de Ensino em Artes, Moda e Design, v. 2, n. 2, p. 044067| 068-090.

https://doi.org/10.5965/259446302220180 44

Naidoo, R. J., Kessy, F., Mlingi, L., 2009. Respiratory health of stonecrushers from the informal sector in Tanzania.

Occupational Health Southern Africa, v. 15 , n. 6, p. 6-13.

Packard, T. G., 2007. Do workers in Chile choose informal employment? A dynamic analysis of sector choice, ed. The World Bank.

Ramires, F. J., 2001. Severino na metrópole - A negação do trabalho na cidade de São Paulo. 218 p. Dissertação (Mestrado em Sociologia) - Faculdade de Filosofia, Letras e Ciências Humanas da Universidade de São Paulo. https://doi.org/10.11606/D.8.2008.tde1907 202-105048

Ruzek, W. et al., 2014. The Informal Economy as a Catalyst for Sustainability. Sustainability, v. 7, n. 1, p. 1-12. https://doi.org/10.3390/su7010023

Salèd L., 2018. The Street Vendors Act and the right to puclic in Mumbai. Journal of Urban Research 17-18. https://doi.org/10.4000/articulo.3631

Schneider, F., Enste, D. H., 2000. Shadow economies: Size, causes, and consequences. Journal of economic literature, v. 38, n. 1, p. 77-114. https://doi.org/10.1257/jel.38.1.77 


\section{GESTÃO \& SUSTENTABILIDADE AMBIENTAL}

\section{¿UISUl}

Snow, C. C., 2015. Organizing in the age of competition, cooperation, and collaboration. Journal of leadership \& organizational studies, v. 22, n. 4, p. 433442.

https://doi.org/10.1177/154805181558585 2

Truong, V. D., 2018. Tourism, poverty alleviation, and the informal economy: the street vendors of Hanoi, Vietnam. Tourism Recreation Research, 2018. 43:1, 52-67. https://doi.org/10.1080/02508281.2017.13 70568

Truong, V., 2018. Dao. Tourism, poverty alleviation, and the informal economy: the street vendors of Hanoi, Vietnam. Tourism Recreation Research, v. 43, n. 1, p. 52-67. https://doi.org/10.1080/02508281.2017.13 70568

Valese, A., 2007. Design vernacular urbano: a produção de artefatos populares em São Paulo como estratégia de comunicação e inserção social. 107f. Tese de Doutorado. Dissertação (Programa de Pós-graduação em Design e semiótica), São Paulo, Brasil.

Williams, C. C., 2013. Beyond the formal economy: evaluating the level of employment in informal sector enterprises in global perspective. Journal of Developmental Entrepreneurship, v. 18, n. 04, p. 1350027.

https://doi.org/10.1142/S10849467135002 71

Williams, C. C., 2015. Tackling informal employment in developing and transition economies: a critical evaluation of the neo-liberal approach. International Journal of Business and Globalisation, v. 14, n. 3, p. 251-270.

https://doi.org/10.1504/IJBG.2015.068619

Yatmo, Y. A., 2008. Street vendors as 'out of place urban elements. Journal of Urban Design, v.13, n. 3, p. 387-402. https://doi.org/10.1080/135748008023208 89

\section{Agradecimentos}

Os autores agradecem à CAPES, Coordenação de Aperfeiçoamento de Pessoal de Nível Superior, que possibilitou o intercâmbio de alunos da graduação e da pós-graduação da Universidade Federal do Maranhão para a Universidade Federal do Paraná, por meio do projeto PROCAD, durante o estudo de campo relatado no ano de 2019. Aos discentes da pós-graduação da UFPR, Gabriel Tanner e Camila D. Pereira. Aos professores da UFPR, Prof. Dr. Aguinaldo dos Santos e Profa. Dra. Maria Lucia Okimoto. 